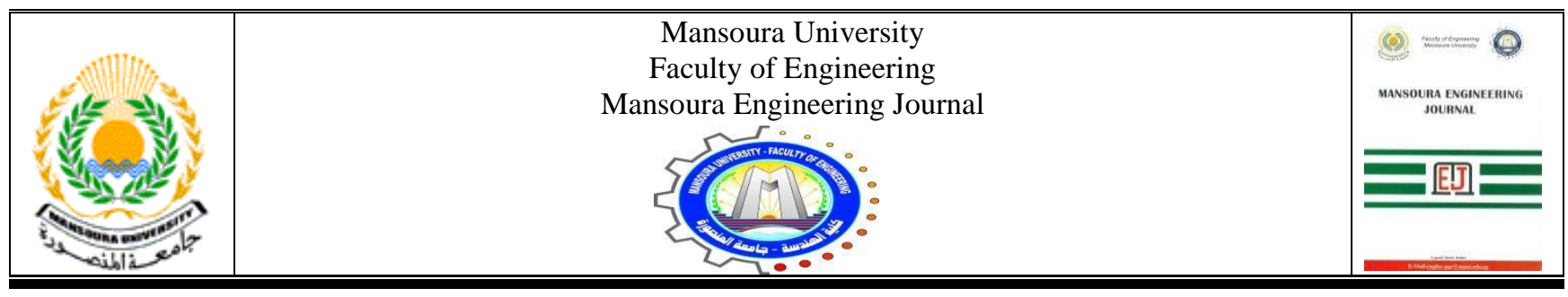

\title{
Embedding Human Dimensions in Architectural Education in Egypt
}

\author{
KEYWORDS: \\ architectural education \\ - Human dimensions- \\ sustainability.
}

\section{Rania A. Ghanam and Asmaa R. Elantary}

Received: (18 January, 2021) - Revised: (21 February, 2021) - Accepted: (02 March, 2021)

Corresponding Author: Rania Abd AL Lateef Ghanam: Department of Architecture, Faculty of Engineering \&Information Technology, Onaizah collages, K.S.A.- Department of Architectural Engineering, Faculty of Engineering, Kafr Alsheikh University, Egypt (E-mail: raniaghanam77@gmail.com)

Asmaa Ramadan Elantay: Assistant Professor of Arch. Department of Interior Design, Jubail University CollageK.S.A. (E-mail: asmaa.elantary@gmail.com)

\section{INTRODUCTION}

$\mathrm{H}$ UMAN being is the center of the existence, so he should be the heart of any action and should be respected by architecture. In traditional ages, man had constituted architecture to suit his personality, culture and to meet his human needs (Taktak 2000) While noting the absence of the human dimension in many contemporary architectural and urban projects, that did not deal with the human dimension as a key element.

The application of engineering and economical standards enhances and supports the application of standard solutions and standard specifications, which leads to the industry of one model and one aesthetic sense (Hamdan,1994). While people, 
races, and groups are governed by different laws, cultures, and values, that suited the lifestyle and requirements of each category. The negligence of human aspects in the architectural and urban design decisions and the focus on the material features only caused sharp changes in the neighborhoods (Madanipour,2006), as in the project Pruitt-Igoe.

Research objective: The research aims to identify which human dimensions are missing in the current architectural curriculum and should be included in the architectural education.

Research methodology: The research follows a qualitative methodology, which is a combination of a theoretical framework that includes a study of the concepts of architectural education, and an analytical approach that studies the extent to which human dimensions are included in the national and international standards of architectural education and practices. In addition, a questionnaire was designed with including all required items to come up with the expertise opinion on the human dimensions' principles and their inclusion in the architectural curriculum. Some interviews were tackled to discuss the importance of suggested elements were analyzed accordingly.

Questionnaire design: The eleven points of human dimensions suggested to be added as important principles in architecture education curriculum were formulated with a Likert five-point scale, starting with 5 for strongly agree and 1 for strongly disagree, the survey was oriented to associate professors at least who are specialized in teaching architectural curriculum in different universities in Egypt.

Results of the survey: The mean for the responses was calculated for each point and the results was discussed in later section of the paper.

\section{THE HISTORICAL RELATIONSHIP BETWEEN HUMAN BEINGS AND ARCHITECTURE.}

Ideological vision was the main component of human thoughts in traditional ages. Consequently, his intellectual and material product was affected by this vision, Architecture and urbanism in these periods were associated with symbols and beliefs. Human being was able to understand the meanings and their accompanying symbols for their compatibility with his culture. There was a sense of belonging to urbanism of these ages, which represented a sincere expression of community and place (Taktak 2007)

In the modernity ages, a cultural interruption took place, which was limited to the material aspects that are completely away from the immaterial aspects like heritage, belief, and culture...etc.

Urbanism and architecture during the modern period developed rapidly to accompany the rapid changes in the world, but at a rate that exceeds the rate of cultural development of society, This led to a break in the continuity of civilization and cultural heritage, which led to the loss of identity and distinct personality ( Al sawee,1994) Urban models were set up by architects in which they would reflect their own personality and ignore the subjectivity of the user, assuming that the user would adapt his living the way they expected (Ghanam,2013)
This led people to be isolated from participating in the formulation of their buildings, which led to the failure of these buildings, As The person who does not participate in the construction of his building feels that he does not belong to it.

People found themselves in a new urban environment completely different with all its elements and its mental image from the traditional counterpart drawn in their minds. Therefore, the symbols hidden in this new environment were not realized by them, as they meant nothing to them. This led to behaviors incompatible with the elements of the built environment, or to the emergence of new behaviors to suit the surrounding and different circumstances (Al Sawee,1994) The phenomenon of acquiring new behaviors causes duplication of values and acceptable social behaviors (Al Sawee,1994) The old values remain alongside with the new values, and the phenomenon of not expecting the behavior of others can cause disturbance. It is translated on a psychological level to tension and anxiety and then alienation and lack of belonging to the surrounding environment (Ankony,1999).

Postmodern architecture tried to take advantage of technological development and restore continuity with cultural and civilizational heritage. Their product has a dual connotation, part of which follows modern architecture and the other follows heritage, revival or popular. The architects aimed to restore social dialogue between people and themselves (Ghanam ,2013)

They took social, human values, and psychological needs as the main sources of architectural thoughts. They depended on the ideas and concepts of pre-modern architecture. These principles attempted to restore the continuity of the mental image in the human imagination by linking the architectural product with certain symbols that are understood and compatible with its users, taken from his heritage or from his local environment, so the architect touched a feeling in the conscience of buildings' users (Taktak,2007)

\section{1- Global issues existing facts}

planners and architects should deal with the fact that 50\% of the populated areas has the urbanization of the planet, they should not look at this fact as a problem but as a force for development (World Urbanization Prospects The 2018 Revision), Also one-sixth of the population of Earth lives in slums and informal settlements, in the next 25 years the population will be doubled, and will live in the same areas, if nothing is done (The Challenge of slums,2003), the gap between the impoverished and the wealthy is increasing and the gap in income has widened significantly (Keeley,2005), which is related directly to access to energy and the growing scarcity of non-renewable resources. Cities will be profoundly affected by the previous facts and their projections; cities will be designed by the poor unless planners and architects will be prepared to meet poverty challenges and human environmental needs.

\section{2-Alienation}

The term alienation is still obscure, philosophers and researchers go with different doctrines in its definition and in 
determining its types, sources, and results. These definitions have been dominated by words such as, isolation, and separation (Al Bostani,1993) ranging from whether alienation is a psychological emotional state of an individual or a species of actual behavior. Alienation is the opposite of belonging and Belonging can be defined as a trend through which a man senses his unification with his group and he is accepted by his group, and alienation is isolation, the inability to prevail with conditions and the lake of sensing the meaning of life (English,1958) ,Studies show that alienation is one of the main features of the current era ((Keeley,2005),Especially, when talking about the problems of society in all philosophical, social, political and health fields, urbanism has not been excluded from that ( El sokoor,2007), The identity lost leads to lake of community participation also it leads to the rejection of laws, social and cultural standards (Ghanam,2013).

\subsection{Relationship between alienation and architecture.}

There are many manifestations of alienation suffered by human beings in the world. A person who is psychologically expatriate because of social life, is himself a disordered person who returns to the formation of this society. Consequently, here lies the danger through which the society is formed based on turmoil. As Abu Hayyan al-Tawhidi sees alienation as the distance that makes a person characterized by contradiction, rupture, loss and anxiety (Key,2005). Karl Marx is one of the first thinkers who links work conditions with the feeling of alienation. He summarized the meaning of economic alienation in that a person lost his ability to express himself and not feel his freedom in his work-related actions. His main problem is that technological development has succeeded in forming a person who is identical to expatriate life without being aware of his alienation (Petrović ,1963)

Architectural alienation is a reflection of all types, forms, and degrees of isolation, whereas the urban spaces are designed to receive all human actions, and they are studied to bear events related to the person and those around him. Any social, political or economic impact has a reflection on architecture and urbanism, and architectural alienation is the transcendence of a person to himself and his humanity by going beyond his capabilities, and his social ties (Al sokoor,2007). It is critical for the architectural profession to take a much stronger role in the fundamental social issues. To do that appropriately, graduates should understand the needs of human dimensions-based approach. This could not be accomplished without considerably changing the basic requirements of architectural programs content, which will certainly change the focus towards a humanitarian architect (Miller,2012).

\section{Architectural EduCation AND human Dimensions}

UNESCO/UIA charter for architectural education development applied in 1996, and in its last edition that was revised in 2017, The Charter constitutes a framework providing guidance to students and teachers of all establishments involved in architectural education. The charter clears that one of its major concerns are the social commitment of the profession and the awareness of the role and responsibility of the architects in their respective societies, and the improvement of the quality of life through sustainable human settlements (Charter UNESCO/UIA for architectural education,2017). The charter confirms the importance of Cultural Ability to act with knowledge of historical and cultural precedents in local and world architecture. The charter also confirms the importance of The Social Studies Ability to act with knowledge of society, society member's needs, and defining contextual requirements for different built environments, understanding the social context and the awareness of philosophy, politics, and ethics as related to architecture (Charter UNESCO/UIA for architectural education,2017).

So, education is the first defense line which can be used to face current and future problems. The above-mentioned relation, between architecture and the society and the problems related to the lack of proper application of human dimensions after graduation, are resulting from the paucity of the human dimension teaching and application during the period of study.

\section{ARCHITECTURAL EDUCATION CURRICULUM AND THE EXISTENCE OF THE HUMAN DIMENSIONS}

\section{4-1 architectural education}

There are so much pressures on the curriculum of architecture school. Graduates and the profession both have expectations, they make demands on the curriculum to meet these future expectations, which is very frustrating. One of the reasons for is the conflicting definitions of the role of architects (Bristol,2011), there are competing prognostications about the profession's future and architecture schools have the responsibility of educating and training architects of the quickly changing future for the profession (Ban ,2014)

There are many boards recognized nationally and internationally, the two largest boards are the Royal Institute of British Architects in the UK (RIBA), and the National Architectural Accreditation Board in the US (NAAB), they both have similar process, and they are the primary route for the registration of an architect (Bentley,2010). The universities that are not in the UK or the USA or a member of the UIA, choose a board to approve their architecture program, so that affect where their graduates can work in the world by affecting how the university design the course structure (El Feki, Kenawy,2018)

\section{4-2 Human dimensions in The Royal Institute of British Architects (RIBA) in the UK.}

The General Criteria (GC) of RIBA part 1 and RIBA part 2 combine different approaches related to aesthetic aspects, technical requirements, and user needs (Bentley,2010). There are eleven main criteria with three subcategories in each one, where three general criteria of them "GC 2,5,6" focusing on the adequacy of the gained knowledge to user needs and social impact. This typifies about $27 \%$ from the total required skills 
(RIBA procedures for validation and validation criteria,2011). The general criteria number 2 is concerned about the suitable knowledge of history, theory, technology, art, and human sciences. It focuses on three main points where the graduate will own the needed knowledge related to culture, social science, and history which affect the buildings' design. While demonstrating a critical and reflective approach (RIBA procedures for validation and validation criteria,2011). General criteria number 5 is totally about understanding the relationship between humans, buildings, and the environment. It aims to connect the buildings and their surroundings with human needs. Besides, enhancing the understanding of the building impact on the environment and the relation with sustainable design aspects (Bentley,2010). The general criteria number 6 is about identifying the architecture function and the architect role in society. Especially, in designing projects concerned in social dimensions. The architect will be responsible for the profession's nature and the commitment towards the clients and the society needs alike. Likewise, the expected influences for the new projects on the existing and anticipated societies. This can be looked at as the impact of architecture on community (RIBA procedures for validation and validation criteria,2011).

\section{4-3 Human dimensions in The National Architectural Accreditation Board (NAAB) in the US.}

The NAAB student performance criteria (SPC) 2020 edition, Student Learning Objectives and Outcomes, holds all the updated needed skills, knowledge, qualities, and practices which students require to graduate effectively. These criteria have four main areas with 26 essential outcomes (Bentley,2010). Out of these 26, there are four areas related to the human needs and social factors in buildings' design under two different criterions.

SC.1 for Health, Safety, and Welfare in the Built Environment is concerned about how the program ensures that students understand the impact of the built environment on human health, safety, and welfare at multiple scales, from buildings to cities.

Under realm A, critical thinking and representation, there are two points, A7 and A8, where the history and global culture and cultural diversity and social equity are essential factors (The National Architectural Accrediting Board,2014).

Under realm B, Building Practices, Technical Skills, and Knowledge; the most important point is the impact of the architect's decisions on the environment, B1 is the pre-design, where the user needs profile is vital. B2 is for the site design, where studying the urban context in a responsive way is crucial. These 4 spots are about $15 \%$ of the total SPC which indicates the importance of such studies in the accreditation board (The National Architectural Accrediting Board,2014).

\section{4-4 Human dimensions in NATIONAL ACADEMIC REFERENCE STANDARDS (NARS) FOR ENGINEERING in Egypt}

The national framework 2nd edition 2018 determines the guidelines and requirements for all engineering discipline to make sure graduates are ready to fulfill the market needs. it sets general expectations about the qualifications and attributes of all engineering fields. Concerning the architecture discipline which is a collective major, where students learn about human and physical science, humanities, and fine/applied arts. So, architecture is a multidisciplinary specialty, where the graduate is accountable for creating sustainable relations between the past, present and the future (NARS,2018).

In addition, graduates must be able to produce designs that meet building users' requirements through understanding the

relationship between people and buildings, and between buildings and their environment; and the need to relate buildings and the spaces between them to human needs and scale.

\section{V.THE HUMAN DIMENSIONS AND SUSTAINABLE URBAN DEVELOPMENT}

\section{5-1 The human dimensions included in the global vision seeking to achieve sustainable urban development (The City We Need 2.0 (TCWN 2.0)).}

The city is a manifesto of principles suggesting ways to achieve sustainable urban development, it was launched prior to the seventh session of the world urban forum partners of the first urban thinkers Campus which involved 14 constituent partner groups, Then 26 urban thinkers campuses had established and their outcomes were the city we need 2.0 basis, which was the main contribution of the world urban campaign to the habitat 3 process, In March 2016, the world urban campaign steering committee adopted unanimously the final draft of the city we need 2.0 , then the WUC Secretariat formally submitted it as the main contribution of the World urban campaign to the Habitat process (TCWN 2.0 ,2016).

\section{5-2 Basic principles in TCWN 2.0}

This global vision for achieving sustainable urban development in the $21^{\text {st }}$ century (TCWN 2.0) depends on achieving 10 main principles and is linked to promoting the realization of many human dimensions, including socially inclusive, affordable, accessible and equitable urbanism, economically vibrant and inclusive urbanism, collectively managed and democratically governed, fostering cohesive territorial development, regenerative and resilient city, sharing identities and sense of place, well planned, walkable, and transit-friendly,safty, healthy and promoting well-being urbanism and learn and innovate urbanism (TCWN 2.0 ,2016).

5-3 A comparison between the human dimensions that are embedded in each of national and international standards of architectural education (NARS-RIBA-NAAB), and a global vision to achieve sustainable urban development (TCWN2.0), (table 3) 
TABLE (3)

RESULTS OF THE ANALYTICAL PART OF THE RESEARCH - SOURCE: THE RESEARCHERS

\begin{tabular}{|c|c|c|c|}
\hline $\begin{array}{l}\text { Basic Requirements of Accreditation } \\
\text { that Related to Human Dimensions }\end{array}$ & (Nars) & $\begin{array}{l}\text { (Riba- } \\
\text { Naab) }\end{array}$ & $\begin{array}{c}\text { (Tcwn } \\
2.0)\end{array}$ \\
\hline Human needs & () & (1) & () \\
\hline Sustainable design principles & (1) & (9) & \\
\hline Impact of architecture on community & (2) & (3) & (2) \\
\hline Cultural life of the community & (2) & & () \\
\hline Social concerns & (9) & & (2) \\
\hline Urban identity & (0) & & \\
\hline welfare & (1) & & (2) \\
\hline Global cultures & & (3) & \\
\hline Cultural diversity & & (2) & (2) \\
\hline Social intellectual & & (3) & \\
\hline Cultural intellectual & & (1) & \\
\hline Social equity & & (3) & (2) \\
\hline Social diversity & & & ()) \\
\hline Social contentment & & & (1) \\
\hline Social inclusiveness & & & (9) \\
\hline Citizenship creation & & & (2) \\
\hline Community participation & & & (2) \\
\hline Urban safety & & & ( ) \\
\hline Urban health & & & (9) \\
\hline economically inclusive urbanism & & & (9) \\
\hline
\end{tabular}

Through the previous comparative analysis, we find that there are number of concepts and human dimensions that have been emphasized in (TCWN2.0) however these human dimensions have not been emphasized in (NARS), nor in (RIBA-NAAB).

Therefore, and through the above, the research presents its future vision for the development of architectural education in Egypt by including more concepts and human dimensions to achieve an important and main goal of architectural education, which is to reach a generation of architects with positive contributions in solving the problems of their society.

\section{EMBEDDING HUMAN DIMENSIONS IN ARCHITECTURAL EDUCATION IN EGYPT (ARCHITECTURAL CURRICULUM RESPONSES TO THE HUMAN DIMENSIONS)}

Architectural curricula must include human dimensions' principles in order for future architects to be better prepared to participate in decision making, the research does not call for the complete overhaul of the curriculum but rather a shift in emphasis, human dimensions must be more include in the curriculum and in practice as well, so the research suggests a curriculum that address some important issues while meeting the basic requirements of accreditation.
6-1 human dimensions that should be promoted in Architectural education curriculum.

\section{6-1-1 social dimensions}

a-Social equity

Recognizing gender differentiated needs and supporting women as key actors in planning and adopting measures that enhance their involvement. engaging residents of slums and informal settlements in improving their quality of life.

b-Social contentment by cultivating a strong sense of community.

c-Social diversity (the diversity and mixing of human activities)

Encouraging partaking in social and cultural life to all segments and age groups of the population.

$d$-Community participation

- Recognizing and integrating divergent interests, lifestyles, and values of different city dwellers through more effective civic engagement, particularly during the planning to implementation stages for local and city-wide projects.

- Recognizing that inhabitants are co-owners of the public space, which are designed with their participation.

- Community participation in public services designing.

- Promoting effective partnerships and active engagement by all members of society and partners (public, private, and civil society).

- Inhabitants are equipped with the knowledge and means to express their views on issues affecting their quality of life.

- Empowers communities to be self-supporting, developing local capacities and supporting local leadership.

- Recognizes the important roles that women fulfill in their respective communities and strengthens their participation in urban and local decision making.

- All inhabitants can participate in and interact with planning, decision-making and project implementation.

e- Society inclusiveness including the needs, safety and dignity of women, elderly, children and youth, persons with disabilities and marginalized groups in public services designing improving access by women and low-income and disadvantaged groups in planning Land, infrastructure, housing, transport, and basic service.

\section{6-1-2 cultural dimensions}

a- cultural diversity embracing cultural diversity (including differences of belief and language) and developing local solutions to urban challenges through using local culture and heritage, local skills, materials and knowledge.

b- global cultures resilient learning community that responds to changing needs of its population in the context of an ever-changing world

\section{6-1-3 human needs (safe, health and promotes well-being)}

a- safety violence, conflict and crime free, (welcoming night and day, inviting all people to use its streets, parks, and transit without fear and guarantees the safety of women and girls and the elderly in both public and workplaces It does so by involving men and women and girls and boys in the planning, design, budgeting and implementation of security interventions) 


\section{b- Health}

1. accessibility to nature and recreation (parks and gardens) for all residents, including the elderly and persons with disabilities.

2. address the rising tide of non-communicable diseases (NCDs) associated with obesity, unhealthy diets, sedentary lifestyles.

3. recognizing health as a fundamental aim of development, co-equal with other aims, and the impacts on health of actions in all urban sectors should be explicitly considered.

4. ensure universal access to safe drinking water, adequate sanitation, and decent shelter.

5. designing urban public spaces to actively promote aesthetic experiences.

6. recognizes the importance and role of art in creating uniquely distinguishable and aesthetically pleasing places.

\section{6-1-4 economically inclusive urbanism}

- recognizing the role and potential of the shared economy both as means to make public services more affordable and accessible and to promote local economic development.

- recognizing that the informal sector of the economy provides an important source of livelihood for the urban poor especially for women.

- encouraging and fostering local economic development from the smallest entrepreneur to the largest corporations and the affordable urbanism and architecture

6-2 Measuring the inclusion of the human dimensions in architectural education in Egypt through experts' opinion questionnaire

Through the method of the questionnaire from faculty members in a number of Egyptian universities, the questionnaire is based on a number of questions, each of them measures one or several directions to achieve the objectives of the paper, and then by analyzing the resulting information, several results could be reached, the suggested points were added in a survey to come up with the level of their importance in the architectural curriculum. The survey was targeting expertise teaching architectural courses in different universities in Egypt, based on the expertise opinions and interviews, who are ranked as professors or associate professors at least, they ranked the points on a five Likert scale which deemed to be added in the curriculum as follow.

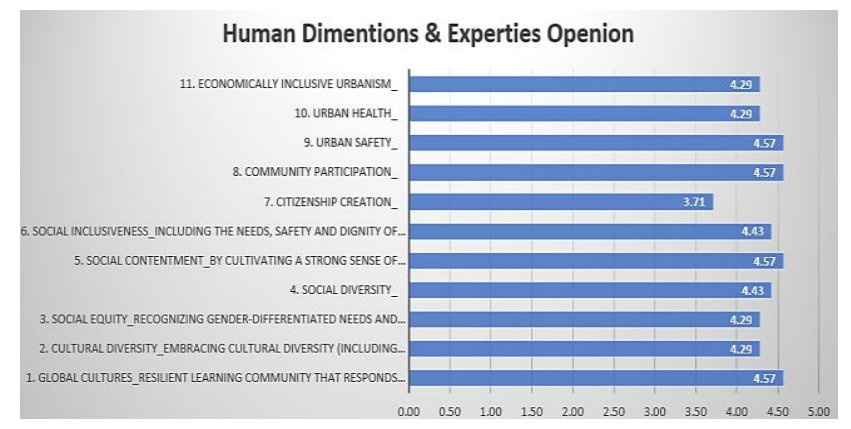

(figure 1) Human dimensions and expertise opinion questionnaire Source: the researchers
All architectural education expertise who participate in the questionnaire strongly agreed with (more than 4.57 out of 5) 10 points out of eleven items suggested to be included in the architectural curriculum.

There are 4 principles that the experts ranked the highest as a priority, they are the inclusion of the urban safety, community participation, social contentment, and global culture concepts.

- There are 6 principles that should be more impeded in the architectural curriculum that are urban health, economically inclusive urbanism, cultural diversity, social equity, social diversity, social inclusiveness.

- The eleventh point, which is related to the citizenship creation, got 3.71 out of 5 which indicates they agree on its existence as well

- Through interviews, the same agreement on the importance of the above elements arose. The experts expressed their willingness to see these principles practiced by the faculty and students alike

- It is evident that the suggested principles are important to be part of the architectural courses. The inclusion of these elements can go gradually starting by studio courses through other parts of related courses till we reach an acceptable level of implementation. This will reflect on the quality of lives architects create every day.

\section{RESEARCH RESULTS AND RECOMMENDATIONS}

\section{7-1 Research results}

- -Architecture will be affected by some global issues existing facts like the rabidly increasing urbanism and the phenomena of alienation, so architectural schools should be prepared to meet these challenges as they have the responsibility of educating and training architects for the quickly changing future of the profession. It is critical, both ethically and practically, for the profession to take a much stronger role in the fundamental social and cultural issues of the 21 st century.

- There are some important human dimensions principals missing in the national standards of architectural education(NARS) as the concepts of global cultures, cultural diversity, social and cultural intellectual, and social equity although these principles are existing in some international standards (NAAB-RIBA).

- By measuring the inclusion of the human dimensions in architectural education in Egypt through a questionnaire for the architectural education experts in Egypt, they strongly agreed that some concepts must be more included in the architecture curriculum as:

The inclusion of the urban safety, community participation, social contentment, global culture concepts, urban health, economically inclusive urbanism, cultural diversity, social equity

\section{7-2 Research recommendations}

- David Orr pointed out that "all education is environmental" (Orr,1991), and the research will add also the concept of "Architecture program with a focus on community development." 
- Architecture schools should take responsibility for applying their knowledge and expertise to meet basic needs in communities.

- The curriculum should address human dimensions' principles by preparing architecture students through community design which will be centered around the studio which will give the students opportunity to engage in vulnerable communities in their region.

\section{REFERENCES}

[1] Alsokoor.Sakr, Humanization of Architecture, Towards a Humanistic Theory in Architecture unpublished PhD Thesis, Faculty of EngineeringCairo University, 2007

[2] Almanzalawe, Alaa-The impact of the human dimensions on the urban pattern as an entry point to achieve the quality of urban life, unpublished $\mathrm{PhD}$ Thesis, Department of Architecture, Faculty of EngineeringMansoura University, Egypt, 2016

[3] Ankony, Robert, The Impact of Perceived Alienation on Police Officers: Sense of Mastery and Subsequent Motivation for Proactive Enforcement, Policing: An International Journal of Police Strategies and Management, vol. 22, (1999)

[4] Barbosa Lara, The value of humanitarian design: The case of the apis project, $11^{\text {th }}$ European academy of design conference, 2015

[5] Bristol Graeme, Human Rights in Architectural Education e, UIA Congress Conference, Tokyo, 2011.

[6] Ban Shigeru, Humanitarian Architecture, Aspen Art Press, 2014

[7] El Feki.Sameh, Kenawy Inji, Integrating Sustainability within architectural education in Cairo, Journal of Proceedings of science and technology,2018.

[8] English Bdwell, English Ava, A Comprehensive of Psychological and Psychoanalytical Terms-Longmans, Green,1958.

[9] Ghanam Rania, The Urban Character Role in Upgrading the cultural Behavior in The New Cities, Case Study New Damietta, unpublished $\mathrm{PhD}$ Thesis, Department of Architecture, Faculty of EngineeringMansoura University, Egypt, 2013

[10] Hemdan. Gamal, The Character of Egypt: A Study in the Genius of Place, Part Four, Dar Al-Hilal, 1994

[11] Miller James, Redefining Humanitarian Architecture with Complexity in Mind: Moving toward a new practice,

[12] Key Alexander, The Applicability of the Term" Humanism" to Abû Hayyân al-Tawhîd, Studia Islamica ,2005

[13] Keeley. Brian, Income Inequality: The Gap between Rich and Poor, OECD Insights, OECD, Publishing, Paris ,2015

[14] Madanipour Ali, Roles and Challenges of Urban Design, Journal of urban design, June ,2006.

[15] Miller. James, Humanitarian Architecture: Application and Concepts, 2012

[16] National Academic Reference Standards (NARS) for engineering, 2nd Edition August 2009

[17] Orr David W, what is education for? Trumpeter, 1991

[18] Petrović Gajo, Marx's Theory of Alienation, Philosophy and Phenomenological Research, International Phenomenological Society Journal, Vol. 23, 1963

[19] Raafat, Ali - Physical creativity in architecture, environment and space, Interconsult Research Center, Giza ,2007.

[20] Rachmawati Murni, Redefinition function in architecture: integration of nature technology and humanity, international journal of academic research ,2011
[21] Royal Institute of British Architects, RIBA procedures for validation and validation criteria, Second Revision 2 May 2014

[22] Taktak, Jackleen, the role of architectural and urban design in developing a sense of belonging in the cultural development of societiesDepartment of Architecture, Faculty of Engineering-Cairo University Egypt- 2002

[23] The City We Need 2. 0, Towards a new urban paradigm, UN Habitat, United Nations Human Settlement Program - 2016

[24] The challenge of slums, global report on human settlements, United Nations Human Settlements Program, 2003

[25] The National Architectural Accrediting Board, 2014 Conditions for Accreditation, approved July 18, 2014.

[26] https://www.worldurbancampaign.org

[27] https://www.naab.org

[28] https://www.worldurbancampaign.org

[29] https://www.du.edu.eg

[30] https://www.hti.edu.eg

[31] https://www.acsa-arch.org

[32] https://www.academia.edu

[33] https://www.arb.org.uk

\section{Arabic Title}

$$
\text { تضمين الابعاد الانسانية في التعليم المعماري في مصر }
$$

\section{Arabia Abstract}

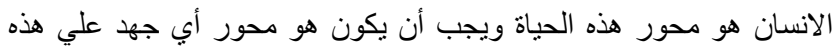

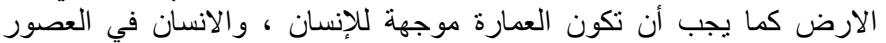

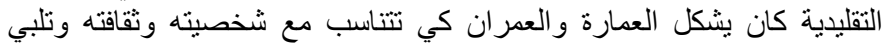

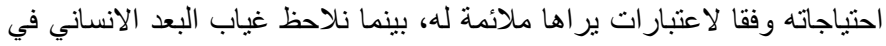

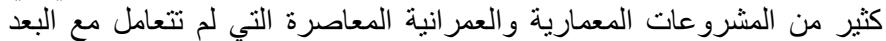

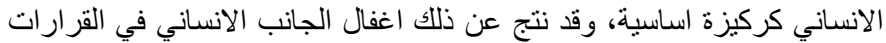

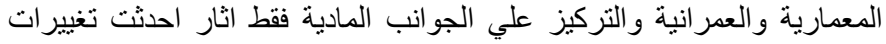

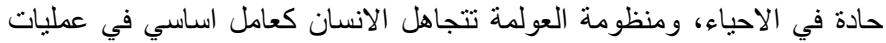

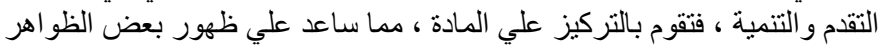

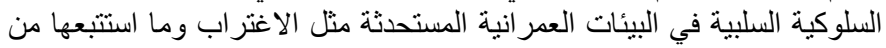

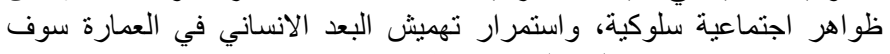

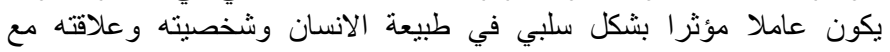
المجتمع .

التعليم المعماري من المجالات شديدة الالتصاق بالمجتمع ومشكلاته ، ويقع

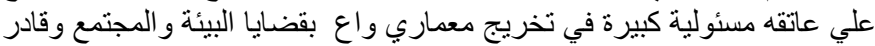

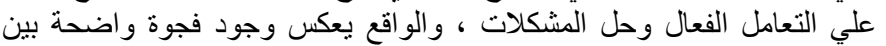

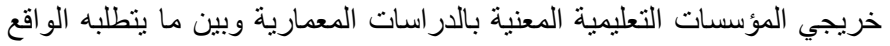

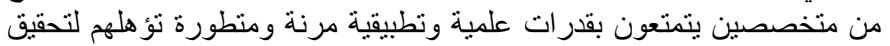

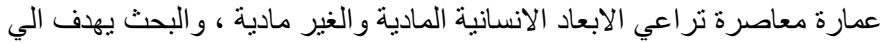

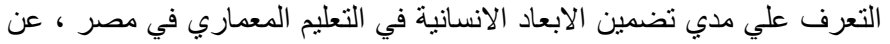

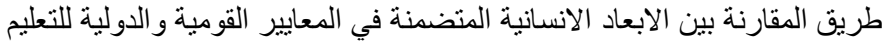

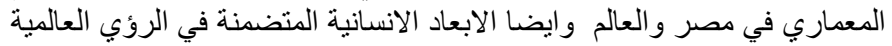

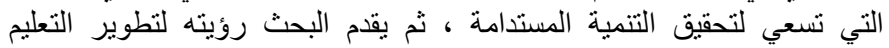
المعماري كي يصبح اكثر انسانية عن طريق تضمين لفئ عدد من المفاهيم الانسانية الهامة. 